\title{
Modeling malaria prevalence rate in Lagos state using multivariate environmental variations
}

\author{
Olusola Gabriel Omogunloye,* Oludayo Emmanuel Abiodun, Olufemi Ayoade Olunlade, \\ Emeka Eusebius Epuh, Ifidon Asikolo and Joseph Olayemi Odumosu \\ Department of Surveying and Geoinformatics, Faculty of Engineering, University of Lagos, \\ Lagos, Nigeria \\ ${ }^{*}$ Corresponding author: oomogunloye@unilag.edu.ng
}

\begin{abstract}
Malaria is the most significant health problem in Nigeria accounting for about $60 \%$ of outpatient consultations and $30 \%$ of hospital admissions (Federal Ministry of Health 2003). The government has identified the burden that malaria places on the health status of the population and has classified malaria as a public health problem. Malaria, though completely preventable and curable, pregnant women and children under five years, are the most vulnerable groups, thus sustainable and evidence based efforts are required to control the malaria disease burden. This research study considered the environmental factors that aid the breeding of malaria carrying vectors. The environmental factors considered in this study are that of rainfall, temperature and relative humidity. The significance of this study centers on how to scale-up malaria related interventions, strengthen of systems, and making a major effort to Roll Back Malaria in Nigeria, (WHO, 2005). The aim of this research is to establish the significant effect of environmental factors on malaria prevalence rate within the Local Government Areas of Lagos State. The methodology used was to carry out a statistical analysis of these various environmental factors with the malaria prevalence cases that was recorded in Lagos State from 2009-2013. GIS was used to show the various local government areas with high severe and low malaria cases. The result obtained from this analysis shows a significant relationship between the malaria prevalence cases and environmental factors of rainfall, temperature and relative humidity, thus leading to development of a predictive model. The outcome of the study can help the government, Lagos state ministry of health and donor agencies at both local and international, identify the local government areas within the state that are most vulnerable to malaria epidemic, and thus providing clear insight in policy formation, planning and strategy implementation.
\end{abstract}

Keywords: malaria, prevalence rate; Lagos; GIS; multivariate variations.

\section{Introduction}

Statistics shows that malaria accounts for nearly 110 million clinically diagnosed cases per year, an estimated 300,000 children die of malaria each year (Federal Ministry of Health 2003). The direct health impact of malaria has led to a severe social and economic burden on our communities and country as a whole, with about N132 billion lost to malaria annually in form of treatment costs, prevention, loss of man hours etc. (Federal Ministry of Health 2003). Malaria control will need to be addressed, not as a separate, vertical, disease-specific intervention, but as part of a health systems strengthening effort, to provide holistic services in all facets of care, and as part of a larger community-development effort (Anyamba, A. et al., (2001); Ghulam, M., et al., (2004); and Guinovart, C., et al., (2006)).

Nigeria, being the most populous country in the continent, accounts for about a quarter of its population. Malaria is the country's most significant public health problem. It accounts 


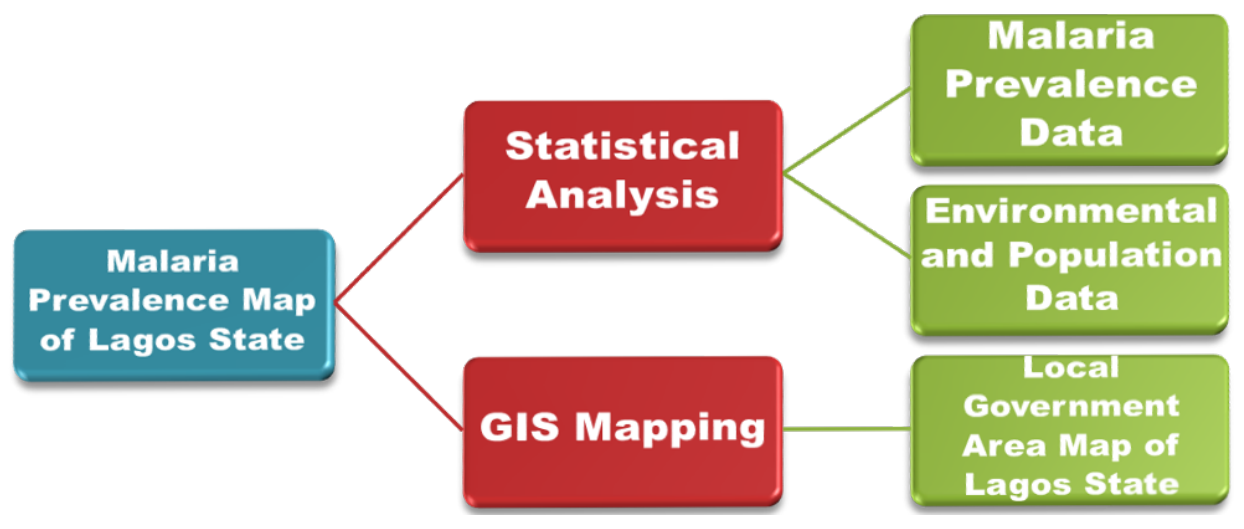

Figure 1: Flow Diagram illustrating the research methodology

for $25 \%$ of under-5 mortality, $30 \%$ childhood mortality and $11 \%$ maternal mortality. At least $50 \%$ of the population will have at least one episode of malaria annually while children aged below 5 years (about 24 million) will have 2 to 4 attacks of malaria annually. While Malaria remains a major public health and development challenge in Nigeria (NMCP (2006); Jason W., (2007); Masound, S. et al., (2008)), we now have a unique opportunity to make a major effort to Roll Back Malaria in Nigeria, (WHO, 2005) . The malaria control plan was built on the National Malaria Strategic Plan (NMSP) for Malaria Control and was developed by the National Malaria Control Programme in partnership with the RBM Partners, States' Ministries of Health and other Stakeholders (Beck, L., et al., (2000); CDCP, (2007 \& 2009); \& Beier JC, et al., (2000)). The global health and malaria community has developed ambitious and overlapping targets with respect to malaria control in Africa.

On April 25, 2000, at the Abuja Summit in Nigeria, the Roll Back Malaria (RBM) Partnership and African health ministers set targets of exceeding 60 percent coverage for these interventions by 2005. Recent surveys indicate that current national coverage levels in Africa for each of the Abuja targets range from 5 to 40 percent. In understanding the fluctuation of malaria incidence rates in the Lagos State and indeed Nigeria at large, it is necessary to examine the requisite environmental conditions needed to support mosquito vector development and proliferation (Bi, P., et al., (2003); Deichman U (1996) \& Brooker, S., et al., (2002 \& 2004)). Analyzing satellite-based remotely sensed environmental data (rainfall, temperature, relative humidity) in a Geographic Information System (GIS) is one approach that can be utilized to identify large geographic areas of suitable mosquito habitat. Exploratory analysis of these habitats can also be employed within GIS to create an effective means for showcasing the areas of malaria transmission to surrounding human populations. It is this approach that can improve understanding about the variations in malaria transmission rates when compared to risk, especially in the Nigeria, where access to conduct epidemiological field studies is limited or restricted.

In the field of epidemiology, which involves the scientific study of factors affecting the health and illness of populations, remote sensing technology plays an integral role in the surveillance of many disease-carrying vectors (e.g., the mosquito and tick). The development of remote sensing technology and GIS has opened new avenues in the study of vector-borne diseases, making it now possible to map the densities of a vector species, model potential disease occurrences, and -continuously monitor the critical environmental habitat needed to support 


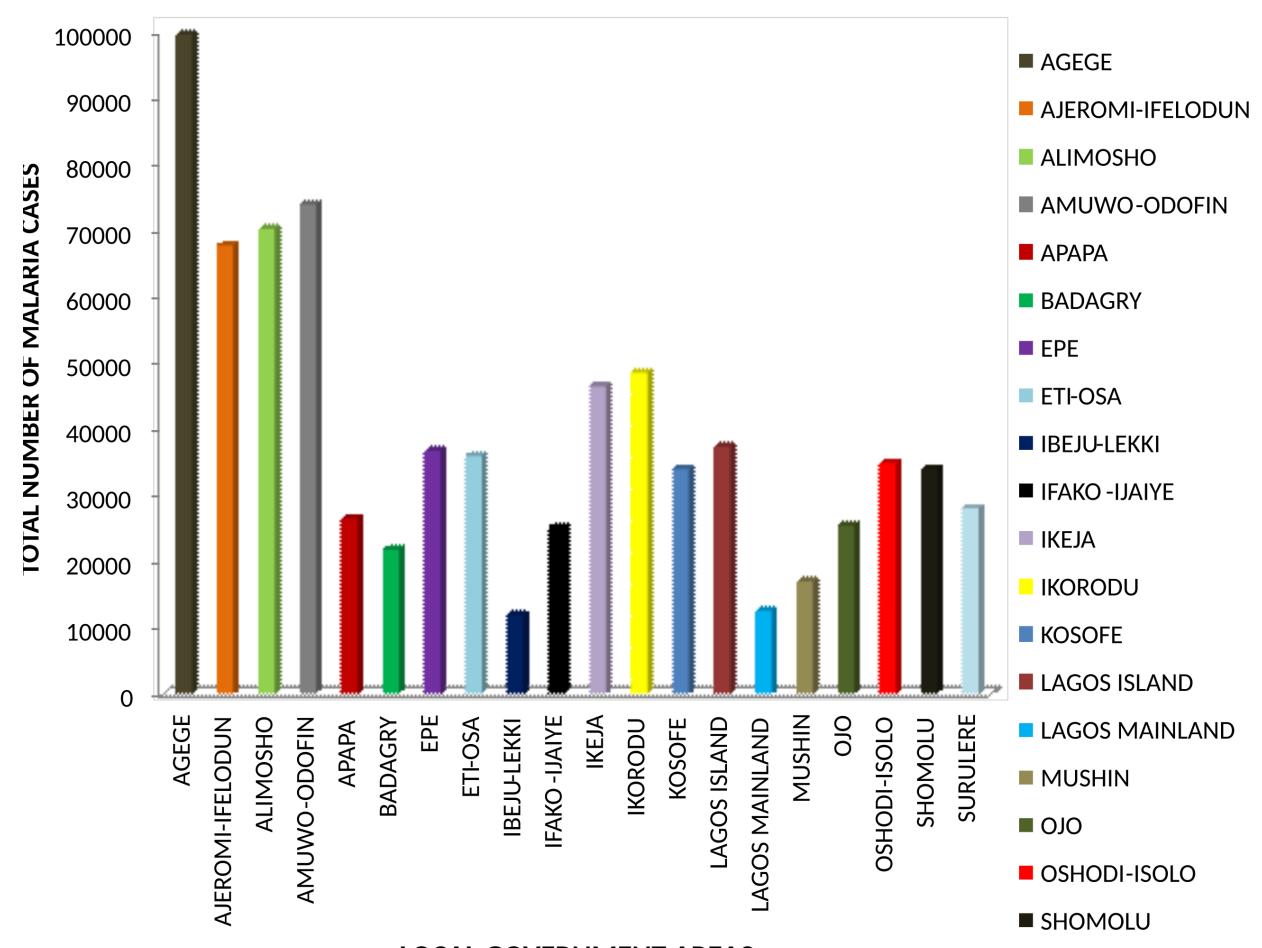

Figure 2: Malaria cases for various LGAs in Lagos State 2009

many infectious diseases (Dhiman 2000). The relevance of developing these technologies appears to be especially important to epidemiologists who have traditionally relied on maps and spatial analysis to link environment to disease (Bruce-Chwatt LJ, et al., (1980); DossouYovo J, et al., (1998) \&Carrat F et al., (1992)).

Early applications of remote sensing technology and GIS to the field of epidemiology came largely from government research. The USA in 1996 for instance, the Department of Defense (DoD), Centers for Disease Control (CDC), and other governmental agencies developed the DoD-Global Emerging Infections Surveillance and Response System (DoD-GEIS) to strengthen existing global epidemiological capabilities for military personnel through the centralized coordination of health organizations and the use of information technology (Culpepper and Kelly 2002). One of DoD-GEIS first implementations was the mapping and surveillance of Rift Valley Fever (RVF) epidemics in Eastern Africa using climatic and terrestrial satellite data. The results -from the project assisted military epidemiologists to streamline medical readiness plans for areas susceptible to RVF outbreaks.

The mapping and analysis of the environmental landscape through remote sensing technology and GIS allows for a better understanding of temporal and spatial aspects of infectious disease transmission. Yet, turning infectious disease characterizations into preemptive intelligence for a given geographic area can be challenging due to variability of the environmental landscape. Brooker et al., (2002) states that reliable intelligence requires an understanding of whether the predictive models developed for one location can be applied to another because the environmental factors that influence transmission are unlikely to be uniform over large geographic areas. That is why validation of such intelligence is vital if it is to be used for 


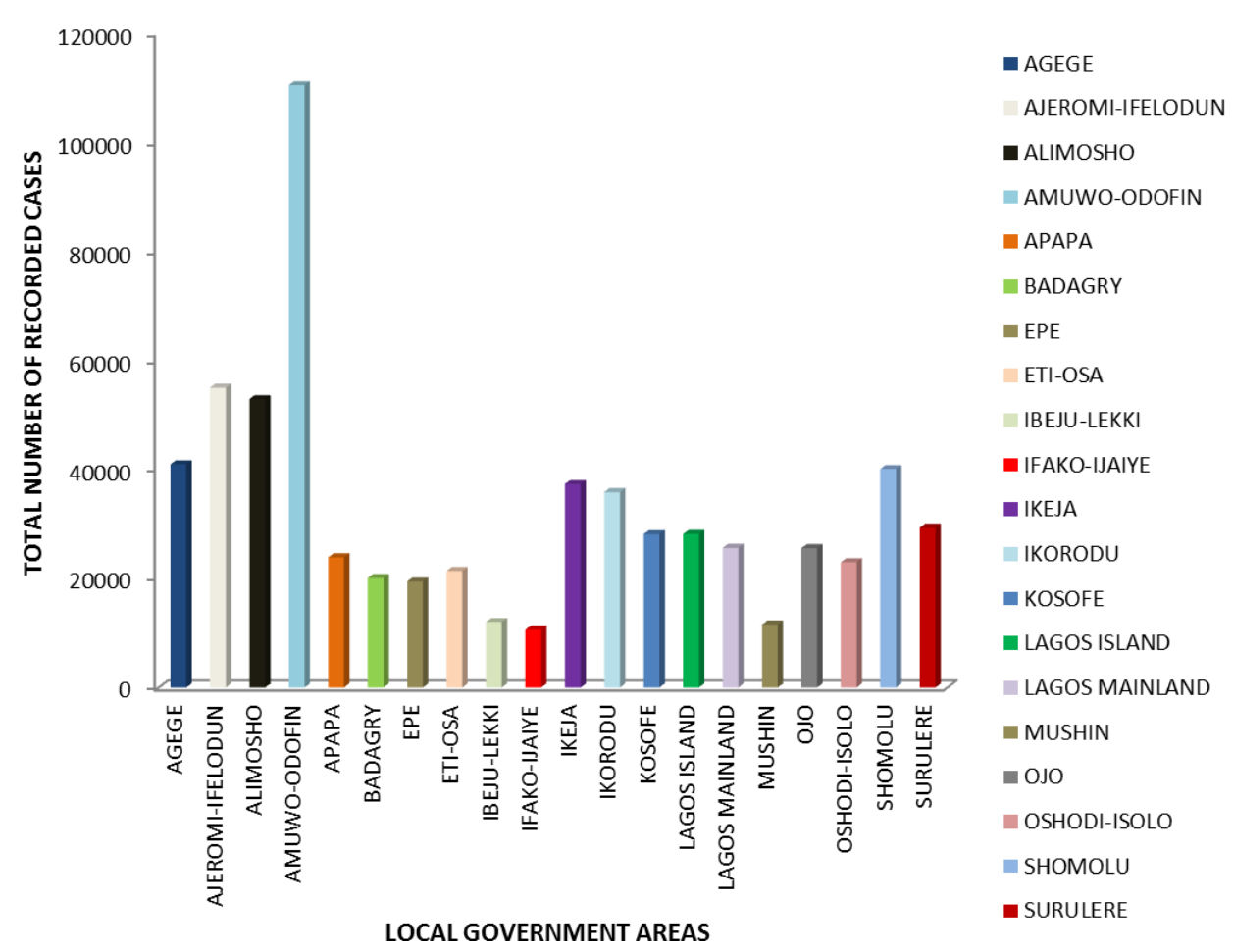

Figure 3: Malaria cases for various LGAs in Lagos State 2010

disease assessment, monitoring, and prevention (Glass, G., (2000); Washino, R., et al., (1994) \& Beatty, M. E., et al., (2007)).

GIS can assist in showcasing these challenges by linking field observations and statistical methods to validate outcomes and create usable information. The development of accurate and defensible- preemptive disease intelligence can help supplement more traditional survey methods of disease as well as facilitate informed decision-making. From an operational standpoint, conventional epidemiological assessments of infectious disease have mostly relied on the investigation of specific diseases from a biological perceptive and the use of syndromic surveillance. Syndromic surveillance is the close field observation of an area for the emergence of a group of symptoms that collectively indicate or characterize disease or abnormal conditions within a population (Sharon 2006). The problem with this method is delayed response and control to a disease outbreak due to late reporting of symptoms, inaccurate information, or sparse public health facilities inadequately prepared to support a population. According to the Centers for Disease Control (Sosin and DeThomasis 2004), there is increased skepticism among public health scientists about the effectiveness of syndromic surveillance as a means for early detection of disease. To mitigate this uncertainty, remote sensing technology and GIS can be used together to complement syndromic surveillance by modeling the specific environmental conditions needed to support the vectors that cause disease. Glass (2000) emphasizes a key point: "GIS is able to calculate variables that are, from a practical perspective, nearly impossible to obtain from field studies." Thus, traditional syndromic surveillance techniques are still useful, but are enhanced when the focus is shifted from disease outcomes and population analysis to exposure and risk. The use of remote sensing technology and GIS modeling can facilitate improved accuracy and quality of risk estimates required to plan for 


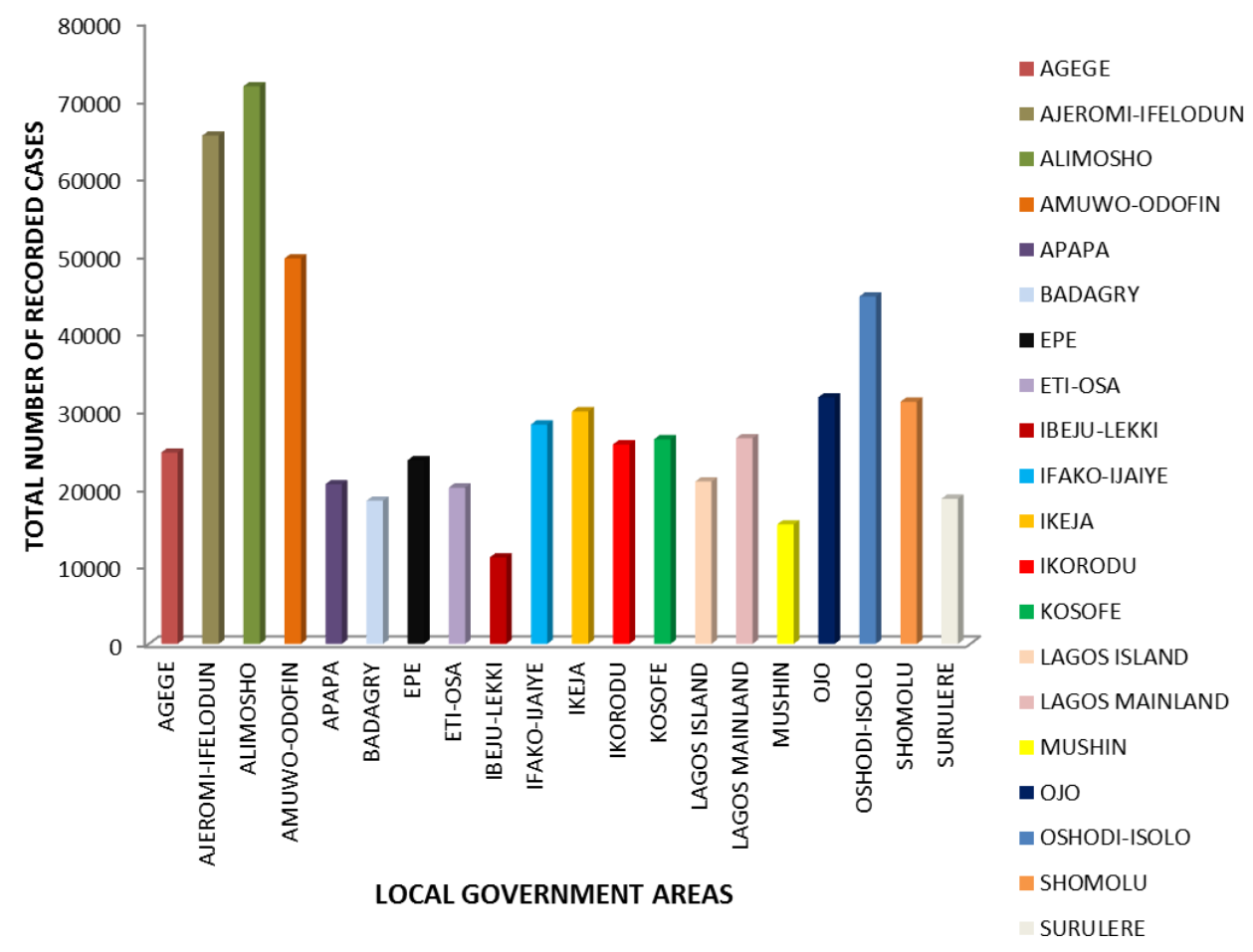

Figure 4: Malaria cases for various LGAs in Lagos State 2011

disease outbreaks before they become widespread human health hazards. Moreover, scientific evidence obtained from utilizing geographic modeling contributes greatly to the theoretical foundation of preemptive disease intelligence, decision support, and response systems, which many countries use to prepare for emerging disease epidemics.

A modeling framework that utilizes remote sensing and GIS technologies has been developed to not only aid in the characterization of disease patterns, but to extend preemptive disease intelligence beyond conventional surveillance. Landscape epidemiology is the process of examining the environmental landscape to observe and ultimately predict disease outbreaks before symptoms appear in a population. This collaborative approach, developed by scientists at NASA's Ames Research Center, involves the identification of geographical areas where disease is transmitted by using holistic approaches involving the interactions and associations between elements of physical and cultural environments (NASA 2006a). Landscape epidemiology theory first conceived by Pavlovsky (1966) follows a fundamental premise; by knowing environmental conditions necessary to support specific pathogens in nature, one can use the landscape to identify spatial and temporal patterns of disease.

One benefit of using the landscape epidemiology framework is that it draws upon a vast resource of archived governmental and commercial remotely sensed environmental data as well as decades of ecological study of disease vectors. Additionally, combining remotely sensed environmental data with GIS and statistical methods can give epidemiologists a practical means to plan and respond to environment attributable, infectious diseases, such as malaria (Culpepper, R., and Kelly, P., (2002); Dhiman, R., (2000) \& Diuk-Wasser, M., et al., (2017)). 


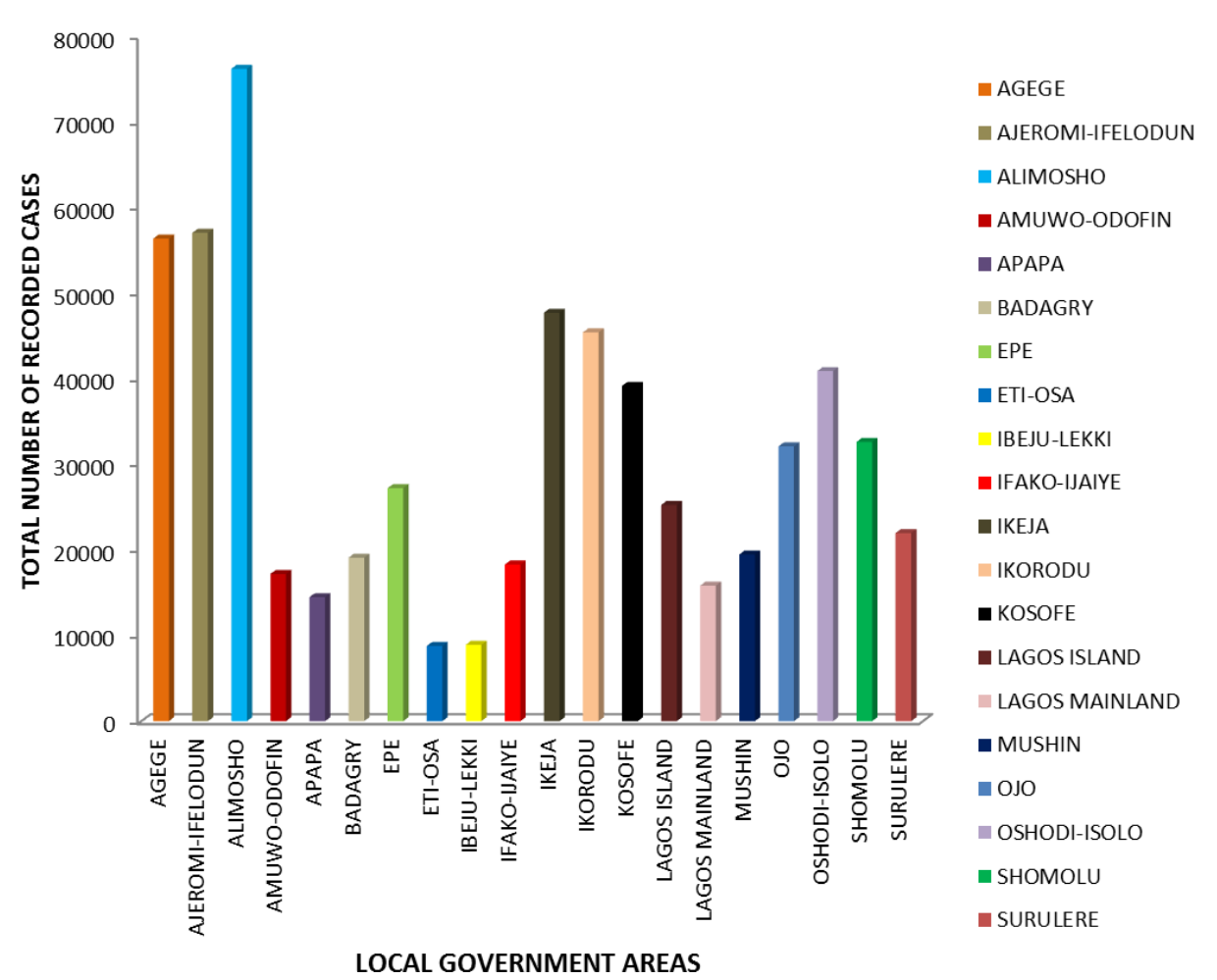

Figure 5: Malaria cases for various LGAs in Lagos State 2012

\subsection{Aim of Research}

The aim of this research is to establish the significant effect of environmental factors on malaria prevalence rate within the Local Government Areas of Lagos State.

\section{Research Objectives}

1. To determine the relationship between environmental variations and prevalence of malaria cases in Lagos state

2. To determine the correlation between the population density of Local government areas in Lagos state and reported cases of malaria by using linear regression model.

3. To determine the significant difference in the prevalence rate of malaria across the seasonal variation in Lagos within a 5years period

4. Produce maps showing the various endemic low and high areas of malaria prevalence in Lagos State

\subsection{Significance of Study}

The significance of this study centers on how to scale-up malaria related interventions, strengthen of systems, and make a major effort to Roll Back Malaria in Nigeria, (WHO, 2005), knowing fully that malaria remains a major public health and development challenge in Nigeria. 


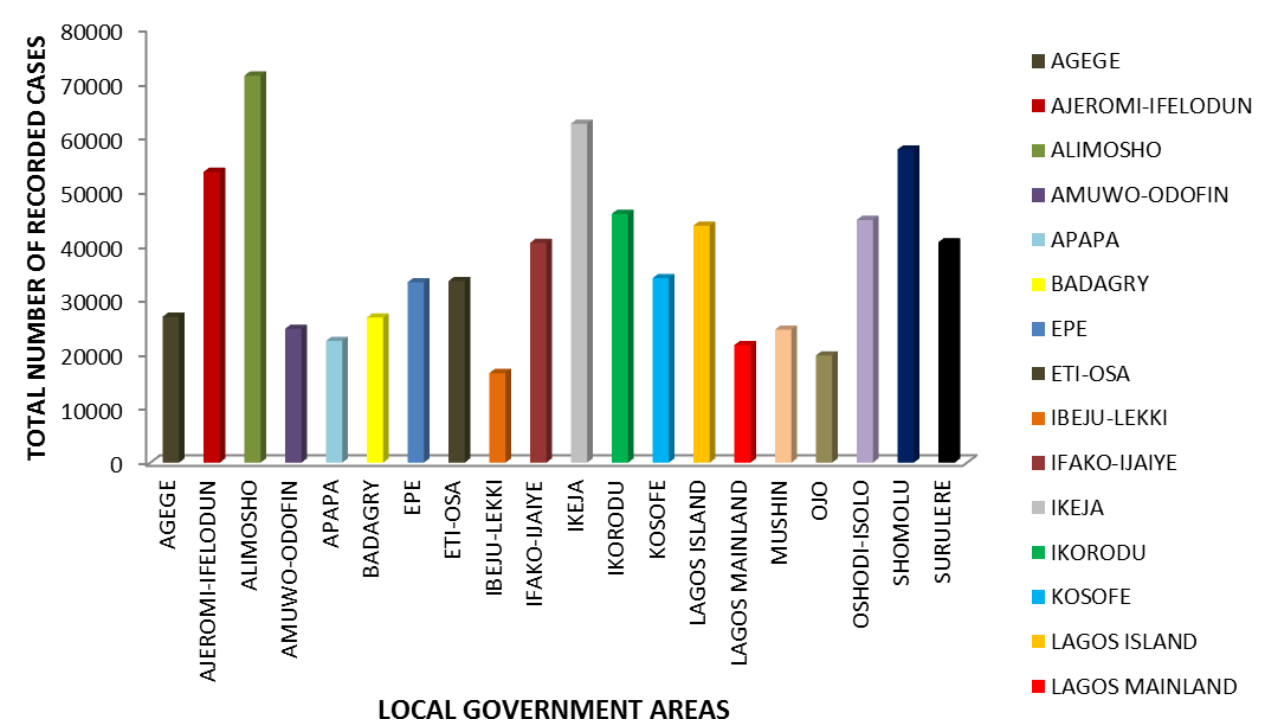

Figure 6: Malaria cases for various LGAs in Lagos State 2013

\section{Definition of Terminology Used}

1. Non-Severe Malaria Cases: These are patient suffering from malaria fever but are not admitted in any medical facilities. These patients are giving prescriptions of drugs by physicians or medical personnel from these health facilities.

2. Severe Malaria Cases: these are patients that are under the watchful eye of the medical personnel in order to monitor and manage their current health conditions.

3. Malaria among Pregnant women: These are malaria cases recorded for women that are pregnant. This covers for only the pre-natal cases and excluded the post-natal malaria cases

\subsection{Study Area}

The study area covers a surface area of approximately 3,345 square kilometers, which is about $0.4 \%$ of the total land area of Nigeria, Lagos is located at $6.5833 \mathrm{oN}$ and $3.7500 \mathrm{oE}$. The state is located in the southwest geopolitical zone of Nigeria, bordered in the north and east by Ogun State, in the west by the Republic of Benin and in the south by the Atlantic Ocean. Lagos State has a coastline of approximately $180 \mathrm{~km}$. Underlain by sedimentary rocks; the State is on a coastal plain characterized by predominantly flat terrain, with an average elevation of less than $1.5 \mathrm{~m}$ above sea level. The land slopes gently from the interior to the sea. Water bodies and wetlands cover over $40 \%$ of the total land area of the state and an additional $12 \%$ is subject to seasonal flooding. The coastal areas consist of lagoons, creeks and swamps, separated from the open sea by a strip of sandy land that varies in width from 2 to 16 kilometers. The entrance into Lagos Lagoon is the only major outlet through which the lagoons and creeks drain into the sea. Wetlands and upland forest (Rain Forest) are the dominant ecozones (FAO (1978); Clarke, K., et al., (1996); Cromley, E, (2003)). In fact, the state falls within the Tropical Rain Forest zone, but the vegetation cover by none built up areas is mostly a mosaic of mangrove swamps, freshwater swamps, secondary forest, 


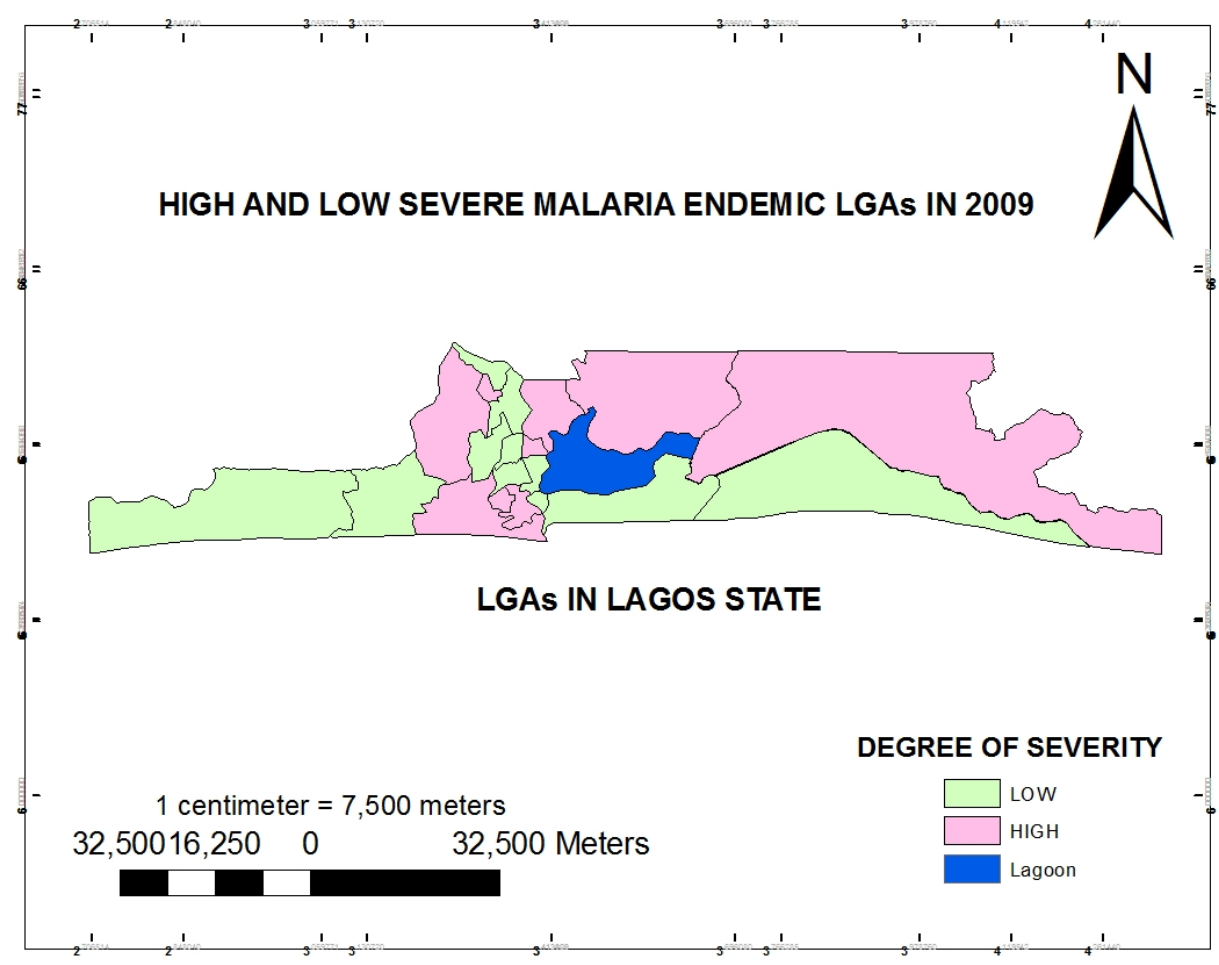

Figure 7: Endemic Local Government Areas in 2009 with both low and high severe malaria cases

farmland and fallow land. The topography is gently sloping throughout and the soils are mostly deep and poorly drained. The state is divided into 5 administrative provinces with 20 Local Government Areas (Local Government Areas) and 37 Local Council Development Areas (LCDAs). It is the commercial center of Nigeria with a population of over 17 million people (LSG 2006 population census).

\section{Research methodology}

The data used for this research work are secondary data gotten from the monthly collated data by the Lagos State Ministry of Health on malaria prevalence for the 20 Local Government Areas within a 5 years period of 2009-2013. These include:

1. Variables such as the monthly non-severe malaria cases, severe malaria cases and malaria in pregnant women during pregnancy for each Local Government Areas of the State for 5years period (2009-2013).

2. Lagos State Population Projection data 2007-2015 by Lagos Bureau of Statistics using Annual Growth Rate of $3.2 \%$. This data is more comprehensive than the population data from the National population census commission.

3. The population density data for various local government areas of the State for the period in view.

4. Environmental data drawn from climatic variables of monthly total rainfall amount, 
monthly average minimum and maximum temperature and the monthly average relative humidity values in percentage as recorded at $0900 \mathrm{z}$ and $1500 \mathrm{Z}$ were obtained from the Nigeria Metrological Station (Nimet) Oshodi.

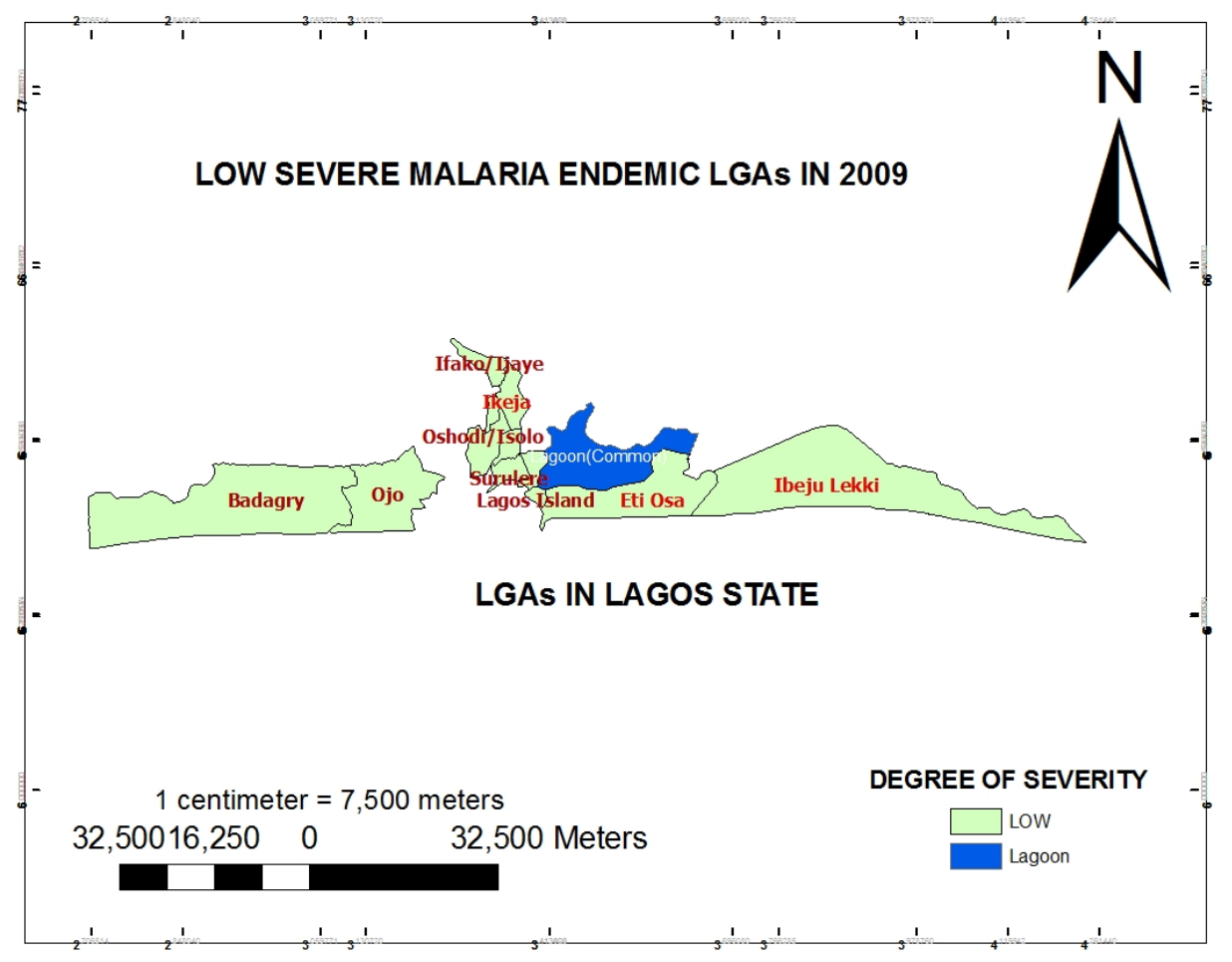

Figure 8: Endemic Local Government Areas in 2009 with low severe malaria cases

\section{Malaria Prevalence Rate in LGAs}

The malaria prevalence rates was derived for each year under various local government area by dividing the malaria prevalence values by the projected population of each local government area multiplied by 100 to give a rate called the malaria prevalence rate

$$
\mathrm{MPR}=\frac{\text { Total annual malaria prevelance in each LGAs in } 2009}{\text { projected population at } 2009} \times 100 \text {. }
$$

It should be noted at this point that this calculation is based on the assumption that the entire population of each local government area was exposed to the risk of malaria during this period, that each person contributed exactly one person per year of exposure. In computing the malaria prevalence rates, the episodes of the subject were considered just as an observed subject for each year.

This MPR was used as the dependent variable in drawing up the regression model for this study. It was also used to correlate with the population density of each local government and the prevalence rate recorded. 


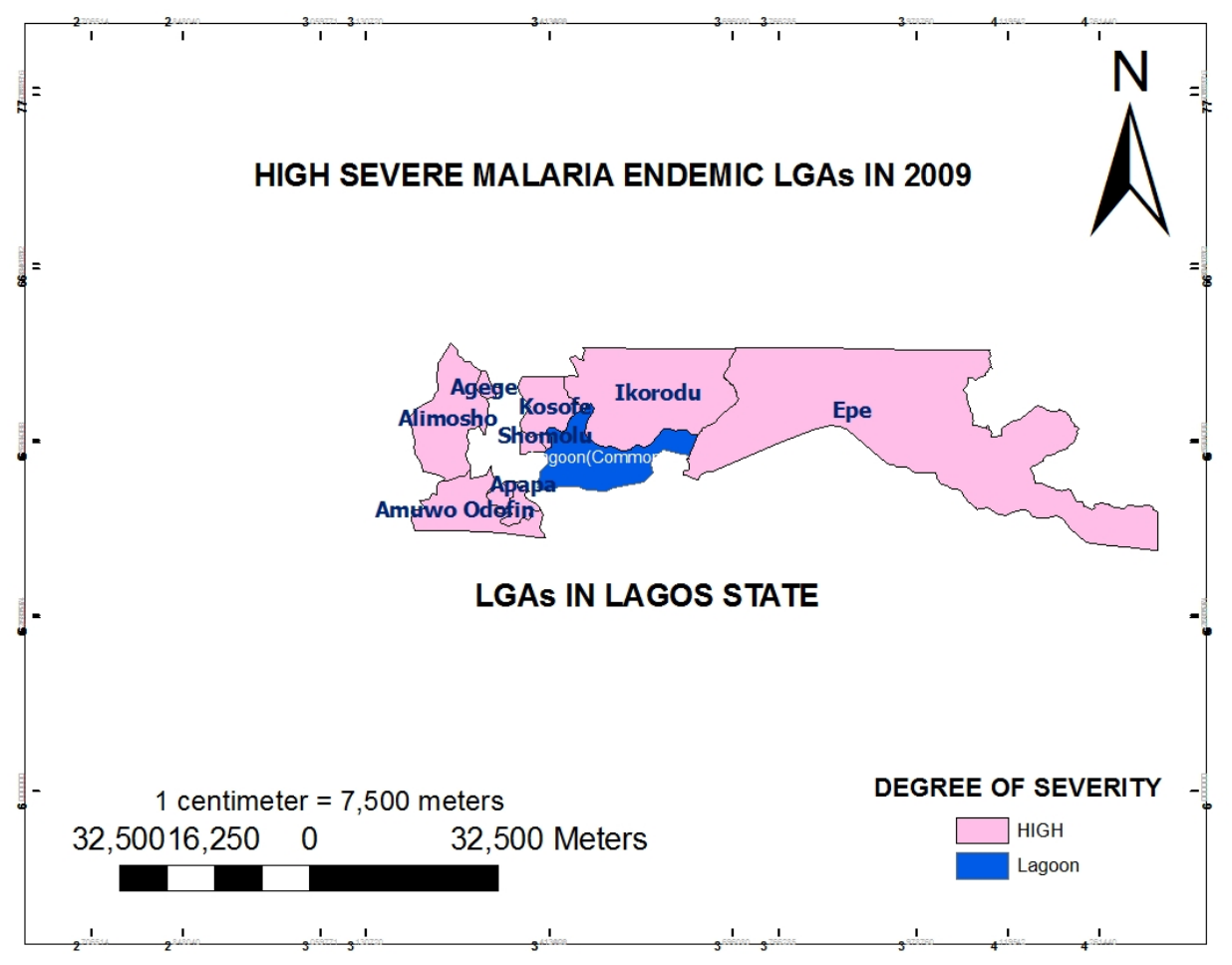

Figure 9: Areas with high severe malaria endemic in 2009

\subsection{Climatic and Environmental Data}

Distribution of malaria is governed by a large number of factors relating to the parasite, the vector and the host (Molineaux 1988). Predominant among these are climatic and environmental factors, particularly those that affect habitat and breeding sites of the anopheline vectors such as temperature, precipitation, humidity, presence of water, vegetation and man to vector contact (Craig MH, Snow et al.,D (1999; Deichman U (1996)). The data used in this study were acquired by the use of GIS and Remotely Sensed data (Rainfall, Temperature and relative humidity) from satellite imagery of same resolution (same scale), for modeling and mapping malaria parasite prevalence, while the environmental predictors are the monthly total rainfall in millimeter, the monthly average minimum and maximum temperature measured in degree Celsius, as well as the monthly average relative humidity values in percentage of $0900 \mathrm{Z}$ and $1500 \mathrm{Z}$ record. The data falls within the period of 5years (2009-2013).

The wet and dry seasons were defined based on rainfall patterns, the months of April-October were classified as the wet season, while November -March were classified as the dry season. This data was used to observe the seasonal malaria prevalence rate during the wet and dry season. Results from this, show a significant difference on the malaria prevalence rate. It was observed that the malaria prevalence rate was lower during the dry season months as to when compared with the prevalence rate of the wet season months (Carmel, et al., (1993); Cheesebrough, M. (2004) \& Epidi, T. T., et al., (2008)).

These environmental figures for malaria prevalence rate were used to derive a regression model analysis using SPSS (version 20). This theory is based on the assumption that all 
other malaria risk factors remain constant.

The method used in this research work comprises three main stages namely Data collection, Data analysis and GIS maps presentation (Figure 1).

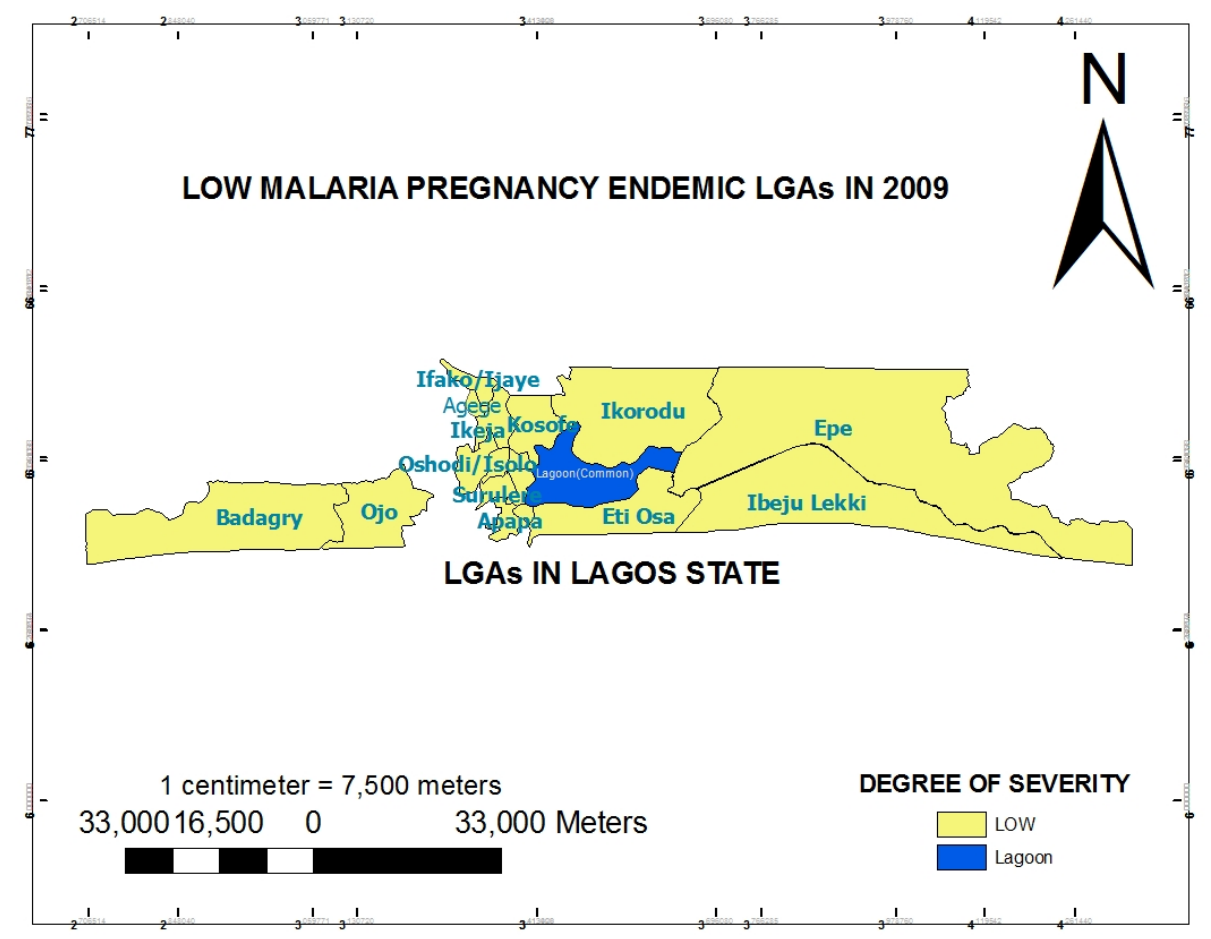

Figure 10: Map representation of Local Government Areas having Low malaria pregnancy endemic in 2009

\subsection{Software Used}

The GIS computing software used in this study was Environmental Research Systems Institute's (ESRI) ArcGIS - ArcInfo with Spatial Analyst version 9.3. Python interpretive scripting language, version 2.4.1, was leveraged to automate data loading, model iteration, and management of image and tabular outputs. SPSS version 20.0 was use to draw up the statistical analysis of all the variables considered. Microsoft Excel was also utilized to apply the statistical formula and to draw necessary chats, used in comparison of the modeled predictor variables values to the observed malaria prevalence rates.

\subsection{Approach Employed}

For the epidemiological description of the data, three inferential statistical approaches were adopted:

1. The use of a regression model, to determine the relationship between spatial environmental variations and the malaria prevalence in Lagos.

2. A correlation approach was used to observe the linear relationship between population density of each local government areas in Lagos and the rate of occurrences for the 
recorded malaria cases.

3. The last approach employed the use of Student Independent sample t- test to determine the mean difference within seasonal variation of Wet and Dry season for malaria prevalence rate in Lagos State.

\subsection{Map Representation}

ArcGIS software, version 9.3 was also used to develop a map where queries were carried out on the administrative map of the 20 local government areas in Lagos state. The various malaria, Non-severe malaria, Severe and malaria cases among pregnant women was represented using various maps to show areas of high endemic malaria regions and low endemic malaria regions.

These maps focus only on 2009 and 2013 with Severe and malaria in-pregnancy in view only. All maps in this study with regard to the study area were spatially referenced (assigned coordinates). Similarly the data that requires scaling (rainfall, temperature and relative humidity) were acquired from satellite imageries of same resolution hence no need for relative scale.

Query builder was used to develop the various malaria endemic map of high and low in the Local Government Areas.

\subsection{Results and Analysis}

Table 1 shows the summary of the various malaria prevalence cases that was recorded from all the local government areas of Lagos State from 2009-2013. In general, a total of 3,363,834 cases of malaria were recorded within the 20 Local Government Areas of Lagos State from January 2009 to December 2013. Among these figures, 2,897,006 (86\%) cases were recorded to be cases of malaria that are non-severe, 323,526 (10\%) are severe cases with malaria fever, while 143,302 (4\%) cases are pregnant women having malaria during pre-natal period.

Table 1: Summary of the various Malaria prevalence cases from 2009-2013 in Lagos State

\begin{tabular}{|l|r|c|}
\hline \multicolumn{1}{|c|}{ Malaria Prevalence Cases } & \multicolumn{1}{c|}{ Cases } & Percentage (\%) \\
\hline \hline Non Severe Cases & $2,897,006$ & 86 \\
\hline Severe Cases & 323,526 & 10 \\
\hline Malaria Among Pregnant Women & 143,302 & 4 \\
\hline \hline Total & $3,363,834$ & 100 \\
\hline
\end{tabular}

Source: Lagos State Ministry of Health, 2014

Table 1 shows the Summary of the various Malaria prevalence cases from 2009-2013 in Lagos State. Table 2 shows the total values of malaria cases as recorded from each Local Government Areas of Lagos State for each year, from 2009-2013. The figures are a combination of both malaria cases of Non-severe, Severe and malaria cases among pregnant women as recorded from each local government area. Furthermore, Figures $(2-6)$ shows a comparative chart of the total malaria cases for each year from 2009-2013 in various local government areas of Lagos State. Figure 2 shows malaria cases for various LGAs in Lagos State in 2009, it shows that Agege LGA has the highest number of total recorded cases with 99,786; other LGAs 
whose figures rose above 60,000 cases were Amuwi-odofin (74,051), Alimosho (70,354) and Ajeromi-ifelodun $(67,861)$. Ibeju-Lekki and Lagos Mainland recorded the lowest number of cases in 2009 with 11,996 and 12,586 cases respectively. Figure 3 shows the malaria cases for various LGAs in Lagos State in 2010, it clearly shows a declined in the malaria cases in the LGAs. This decline (apart from Amuwo-odofin LGA with 110430 cases) falls below 60,000 of recorded malaria cases. Local Government Areas like Ajeromi-Ifelodun, Alimosho and Agege whose figures were above 67,000 cases in 2009 , falls down to below 55,000 cases. Ifako-Ijaiye, Mushin and Ibeju-Lekki LGAs all recorded the lowest values of malaria cases in 2010 with $10,613,11,569$ and 12,028 cases respectively.

Table 2: Malaria cases in Lagos State LGAs from 2009-2013

\begin{tabular}{|l|c|c|c|c|c|}
\hline \multicolumn{1}{|c|}{ LGAs } & 2009 & 2010 & 2011 & 2012 & 2013 \\
\hline \hline Agege & 99786 & 40966 & 24625 & 56393 & 26864 \\
\hline Ajeromi-Ifelodun & 67861 & 54994 & 65409 & 57075 & 53538 \\
\hline Alimosho & 70354 & 52904 & 71756 & 76254 & 71268 \\
\hline Amuwo-Odofin & 74051 & 110430 & 49597 & 17209 & 24656 \\
\hline Apapa & 26528 & 23881 & 20549 & 14495 & 22401 \\
\hline Badagry & 21784 & 20086 & 18423 & 19104 & 26720 \\
\hline Epe & 36767 & 19460 & 23632 & 27238 & 33226 \\
\hline Eti-Osa & 36047 & 21384 & 20108 & 8783 & 33422 \\
\hline Ibeju-Lekki & 11996 & 12028 & 11130 & 8923 & 16494 \\
\hline Ifako-Ijaiye & 25241 & 10613 & 28222 & 18304 & 40476 \\
\hline Ikeja & 46533 & 37326 & 29922 & 47739 & 62420 \\
\hline Ikorodu & 48615 & 35849 & 25669 & 45454 & 45808 \\
\hline Kosofe & 33972 & 28144 & 26328 & 39189 & 33972 \\
\hline Lagos Island & 37379 & 28159 & 20884 & 25266 & 43644 \\
\hline Lagos Mainland & 12586 & 25608 & 26480 & 15840 & 21643 \\
\hline Mushin & 16997 & 11569 & 15380 & 19476 & 24498 \\
\hline Ojo & 25491 & 25571 & 31735 & 32108 & 19726 \\
\hline Oshodi-Isolos & 34927 & 22996 & 44705 & 40923 & 44694 \\
\hline Shomolu & 34118 & 40089 & 31160 & 32635 & 57670 \\
\hline Surulere & 28061 & 29314 & 18676 & 21993 & 40585 \\
\hline
\end{tabular}

Source: Lagos State Ministry of Health, 2014

Figure 3 shows the malaria cases for various LGAs in Lagos State in 2011.Alimosho $(71,756)$ and Ajeromi-Ifelodun $(65,409)$ experienced an increased number of cases different from what was obtained in 2010. It is very important to note that local government like Agege recorded a drastic lower figure in 2011 of 24625 . On the other hand, Oshodi-Isolo local government area witnessed its all-time high of 44,705. Ibeju-lekki $(11,130)$ and Mushin $(15,380)$ remains the local government area with the lowest numbers of cases.

Figure 4 gives the malaria cases for various LGAs in Lagos State 2012, it was observed that Local Government Areas such as Alimosho, Ajeromi-Ifelodun; Agege; Ikeja; Ikorodu and Oshodi-Isolo all had number of cases that are above 40,000, with Alimosho having the highest that is over 70,000 cases. Amuwo-odofin recorded its all-time low cases of malaria prevalence of 17,209. Also in this same year, Local Government Areas such as Mushin and Ibeju-Lekki 
Table 3: Anova malaria prevalence

\begin{tabular}{|c|c|c|c|c|c|}
\hline Environmental Factors & Sum of Squares & $\mathrm{df}$ & Mean Square & $\mathrm{F}$ & Sig. \\
\hline \multicolumn{6}{|l|}{ Max. Temperature } \\
\hline Between Groups & 7531395.180 & 3 & 2510465.060 & 5.162 & .002 \\
\hline Within Groups & 70999784.943 & 146 & 486299.897 & & \\
\hline \multicolumn{6}{|l|}{ Min. Temperature } \\
\hline Between Groups & 2988617.011 & 3 & 996205.670 & 1.925 & .128 \\
\hline Within Groups & 75542563.112 & 146 & 517414.816 & & \\
\hline \multicolumn{6}{|l|}{ Rainfall } \\
\hline Between Groups & 19819263.104 & 4 & 4954815.776 & 12.237 & .000 \\
\hline Within Groups & 58711917.019 & 145 & 404909.773 & & \\
\hline \multicolumn{6}{|c|}{ Relative Humidity at $1500 \mathrm{Z}$} \\
\hline Between Groups & 9879977.503 & 4 & 2469994.376 & 5.217 & .001 \\
\hline Within Groups & 68651202.619 & 145 & 473456.570 & & \\
\hline \multicolumn{6}{|c|}{ Relative Humidity at 0900Z } \\
\hline Between Groups & 10609905.420 & 2 & 5304952.710 & 11.481 & .000 \\
\hline Within Groups & 67921274.703 & 147 & 462049.488 & & \\
\hline
\end{tabular}

recorded their all-time lowest of 8,783 and 8,923 respectively.

Figure 5 gives the malaria cases for various LGAs in Lagos State in 2013. It shows that over 9 Local Government Areas recorded cases that were over 40,000 malaria cases with Ikeja shooting to second highest after Alimosho $(71,268)$ with 62,420 malaria cases. Shomolu had the third higher number of recorded malaria cases of 57,670. Other Local Government Areas cases above 40,000 are Ajeromi-Ifelodun Local Government Area (53,538); Ifako-Ijaiye Local Government Area (40,476); Ikorodu Local Government Area $(45,808)$, Lagos Island Local Government Area $(43,644)$; Oshodi-Isolo Local Government Area $(44,694)$ and Surulere Local Government Area $(40,585)$. Although Ibeju-Lekki still maintain the Local Government Area with the least recorded malaria cases, yet the records still shows a 16,494 malaria cases, while local government such as Ojo and Lagos Mainland falls also within the low range with 19,726 and 21,643 malaria cases respectively.

\subsection{Results of the Statistical Model}

\section{Anova Analysis}

Table 3 shows an ANOVA table of malaria prevalence and environmental factors of Temperature, Rainfall and Relative Humidity. The table gave mean square of 2510465.060 and degree of freedom (df) of 3 between groups in maximum Temperature, and f-value of 5.162, with a p-value of 0.002 , since this p-value is less than 0.05 , this shows a statistical significance effect of maximum temperature to the malaria prevalence in various Local Government Areas of Lagos State within 2009-2013.

Furthermore, the minimum Temperature shows a mean square of 996205.670 with a degree of freedom of 3 between groups, the f-value is 1.925 , however, with a p-value of 0.128 , which 
is greater than 0.05 , this shows a non- statistical significance level of minimum temperature to the malarial prevalence cases in various Local Government Areas of Lagos State.

On the other hand, with a mean square value of 4954815.776, and a degree of freedom of 4 between groups in rainfall, this have a f-value of 12.237 with a p-value (0.001) which is less than 0.05. Thus this has a significant influence on the malaria prevalence in Local Government Areas of Lagos State.

Lastly, the variable of Relative humidity taken at $1500 \mathrm{Z}$ shows a mean square value between groups of 2469994.376 the degree of freedom is 4 and the f-value is 5.217 with a p-value of 0.001 , hence the p-value is less than 0.05 and thus, there is a significant effect on malaria prevalence in the state. While the Relative humidity taken at 0900Z shows a mean square value between groups of 5304957.710 with an F-value of 11.48, this also has a significant effect on the malaria prevalent cases in Local Government Areas of Lagos State because the p-value (0.001) is less than 0.05

The Model Summary gives the value of $\mathrm{R}$ called coefficient of multiple correlations, R2, or coefficient of determination, and the standard error of the estimate. Table 4 gives the coefficient of determination for the model. The most important statistics are the coefficient of determination, which is represented as $\mathrm{R} 2=.133$, and the Std. Error of the estimate $=683.0223$. The coefficient of determination, $\mathrm{R} 2$ is the proportion of variance in the dependent variable that is explained by the model, and it is 13.3 per cent in this case. I.e. about $13.3 \%$ of the malaria prevalence rate in Lagos State is explained by the three independent variables that were examined. The R2 might not have adequately accounted for the malaria prevalence rate.

Table 4: The coefficient of determination for the model

\begin{tabular}{|c|c|c|c|c|c|c|c|c|}
\hline \multirow{2}{*}{ Model } & \multirow{2}{*}{$\mathrm{R}$} & \multirow{2}{*}{$\begin{array}{c}\mathrm{R} \\
\text { Square }\end{array}$} & $\begin{array}{c}\text { Std. Error } \\
\text { of the } \\
\text { Estimate }\end{array}$ & $\begin{array}{c}\text { R Square } \\
\text { Change }\end{array}$ & $\begin{array}{c}\mathrm{F} \\
\text { Change }\end{array}$ & df1 & df2 & $\begin{array}{c}\text { Sig. F } \\
\text { Change }\end{array}$ \\
\hline \hline & .364 & .133 & 683.0223 & .133 & 7.445 & 3 & 146 & .000 \\
\hline
\end{tabular}

Predictors: (Constant), Mean Temperature, Rainfall, Mean Relative humidity

Table 5 shows the ANOVA, summarizes the results of the analysis of variance, showing that the ratio of the variances (mean square) explained by the regression (3473111.919) to the residual or unexplained variance (466519.482), which is an $\mathrm{F}$ ratio, is $\mathrm{F}=7.445$ and the significance of this $\mathrm{F}$ ratio is $\mathrm{p}=0.001$, which is less than $\mathrm{p}=.05$ and is therefore statistically significant by conventional standard. It is reasonable to conclude that the results of the analysis are not merely due to chance.

Table 5: The ANOVA of the model

\begin{tabular}{|c|c|c|c|c|c|}
\hline Model & Sum of Squares & df & Mean Square & F & Sig. \\
\hline \hline Regresion & 10419335.76 & 3 & 3473111.919 & 7.445 & 0.000 \\
\cline { 2 - 6 } Residual & 68111844.37 & 146 & 466519.482 & \multicolumn{2}{|c}{} \\
\cline { 2 - 6 }
\end{tabular}

a. Dependent Variable: Malaria Prevalence Rate

b. Predictors: (Constant), Mean Temperature, Rainfall, Mean Relative humidity 
The F-Statistic: Variation Between Sample Means / Variation Within the Samples. The F-statistic is the test statistic for F-tests. In general, an F-statistic is a ratio of two quantities that are expected to be roughly equal under the null hypothesis, which produces an F-statistic of approximately 1. An F statistic is a value you get when you run an ANOVA test or a regression analysis to find out if the means between two populations are significantly different.

A small $\mathrm{p}$ (probability) - value (typically $\leq 0.05$ ) indicates strong evidence against the null hypothesis, so you reject the null hypothesis. A large p-value $(>0.05)$ indicates weak evidence against the null hypothesis, so you fail to reject the null hypothesis.

Table 6 shows the Linear Regression model: According to the presented results, one can conclude that with the mean temperature $(\mathrm{p}=0.001)$, rainfall $(\mathrm{p}=0.006)$ and mean relative humidity $(\mathrm{p}=0.001)$, these have a significant effect on Malaria prevalence rate in Lagos. In addition, the sign of the estimates tells us that while rainfall has a direct effect, mean temperature and mean relative humidity have an inverse effect on Malaria prevalence rates.

Table 6: Linear Regression model

\begin{tabular}{|c|c|c|c|c|c|c|c|c|}
\hline \multirow[b]{2}{*}{ Model } & \multicolumn{2}{|c|}{$\begin{array}{l}\text { Unstandardized } \\
\text { Coefficients }\end{array}$} & \multirow{2}{*}{$\begin{array}{c}\begin{array}{c}\text { Standardized } \\
\text { Coefficients }\end{array} \\
\text { Beta }\end{array}$} & \multirow[b]{2}{*}{$t$} & \multirow[b]{2}{*}{ Sig. } & \multirow[b]{2}{*}{$\begin{array}{l}\text { Zero- } \\
\text { order }\end{array}$} & \multirow[b]{2}{*}{ Partial } & \multirow[b]{2}{*}{ Part } \\
\hline & B & Std. Error & & & & & & \\
\hline (Constant) & 11420.016 & 1837.426 & & 6.215 & .000 & & & \\
\hline Temp & -187.491 & 42.367 & -.471 & -4.425 & .000 & -.204 & -.344 & -.341 \\
\hline Rainfall & .265 & .595 & .040 & .446 & .006 & .043 & .037 & .034 \\
\hline Relative Humidity & -36.899 & 9.580 & -.422 & -3.852 & .000 & -.083 & -.304 & -.297 \\
\hline
\end{tabular}

Dependent Variable: Malaria Prevalence

Using the unstandardized coefficient the regression model is:

$$
\mathrm{MP}=11420-187.5 \mathrm{MT}+0.3 R-36.9 \mathrm{MRH}
$$

Where MP = Malaria Prevalence

$\mathrm{MT}=$ Mean Temperature in degree centigrade

$\mathrm{R} \quad=$ Rainfall in $\mathrm{mm}$

$\mathrm{MRH}=$ Mean Relative Humidity

Tables 7, 8 and 9 represent the correlation analyses of the population density of the various Local Government Areas and the various malaria cases from these areas based on annual records. Table 7 shows the relationship between population densities by Non-Severe malaria cases 2009-2013

Among the Population Densities by Non-Severe Malaria, Severe Malaria and Pregnant Women Malaria Cases from 2009-2013 in Tables 7, 8 and 9:

- Using Pearson's correlation to assess the population density from 2009-2013, each of the three cases either showed a weak positive or relationship in all the three cases and the Non-Severe malaria cases in 2009, a weak positive or negative direct or indirect relationships were observed between Pearson's correlation and their corresponding population density values, while the p-values for all (Tables 7, 8 and 9) are greater than 0.05. This implies that the three cases observed are not statistically significant and can be attributed to chance variation. 
Table 7: Relationship between population density by Non-Severe malaria cases 2009-2013

\begin{tabular}{|c|c|c|}
\hline \multirow{2}{*}{$\begin{array}{c}\text { Population } \\
\text { Density }\end{array}$} & $\begin{array}{c}|c| \\
\text { Non-Severe Malaria Cases } \\
\text { Coefficient }\end{array}$ & P-value \\
\hline \hline 2009 & 0.149 & 0.529 \\
\hline 2010 & -0.004 & 0.986 \\
\hline 2011 & 0.156 & 0.510 \\
\hline 2012 & 0.254 & 0.280 \\
\hline 2013 & 0.205 & 0.386 \\
\hline
\end{tabular}

Table 8: Relationship between population density by Severe malaria cases 2009-2013

\begin{tabular}{|c|c|c|}
\hline \multirow{2}{*}{$\begin{array}{c}\text { Population } \\
\text { Density }\end{array}$} & $\begin{array}{c}|c| \\
\text { Pearsonere Malaria Correlation } \\
\text { Coefficient }\end{array}$ & P-value \\
\hline \hline 2009 & 0.152 & 0.521 \\
\hline 2010 & 0.137 & 0.563 \\
\hline 2011 & -0.007 & 0.976 \\
\hline 2012 & 0.109 & 0.646 \\
\hline 2013 & 0.318 & 0.172 \\
\hline
\end{tabular}

Student's Independent Sample T- Test

Table 10 gives Student's Independent Sample T-test table. Table 10 shows that when comparing the means of MP within seasonal variation (Wet and Dry seasons), the Wet season recorded a Mean + S.D of $465988.40+65657.476$ of malaria prevalence, while the Dry seasons recorded a Mean + S.D of $213737.40+23514.758$ of malaria prevalence. It was observed that the malaria prevalence was higher in Wet season than in the Dry season with a difference of 252251, however, with a p-value ( 0.004 ) less than 0.05 , this observation is statistically significant, and cannot be attributed to chance thus the malaria prevalence in Wet season is significantly more to the malaria prevalence in Dry season.

Table 9: Relationship between population density by Malaria cases among pregnant women 2009-2013

\begin{tabular}{|c|c|c|}
\hline \multirow{2}{*}{$\begin{array}{c}\text { Population } \\
\text { Density }\end{array}$} & $\begin{array}{c}|c| \\
\text { Malaria Cases among Pregnant women } \\
\text { Coefficient }\end{array}$ & P-value \\
\hline \hline 2009 & 0.085 & 0.723 \\
\hline 2010 & 0.066 & 0.781 \\
\hline 2011 & -0.131 & 0.582 \\
\hline 2012 & -0.007 & 0.976 \\
\hline 2013 & 0.033 & 0.889 \\
\hline
\end{tabular}




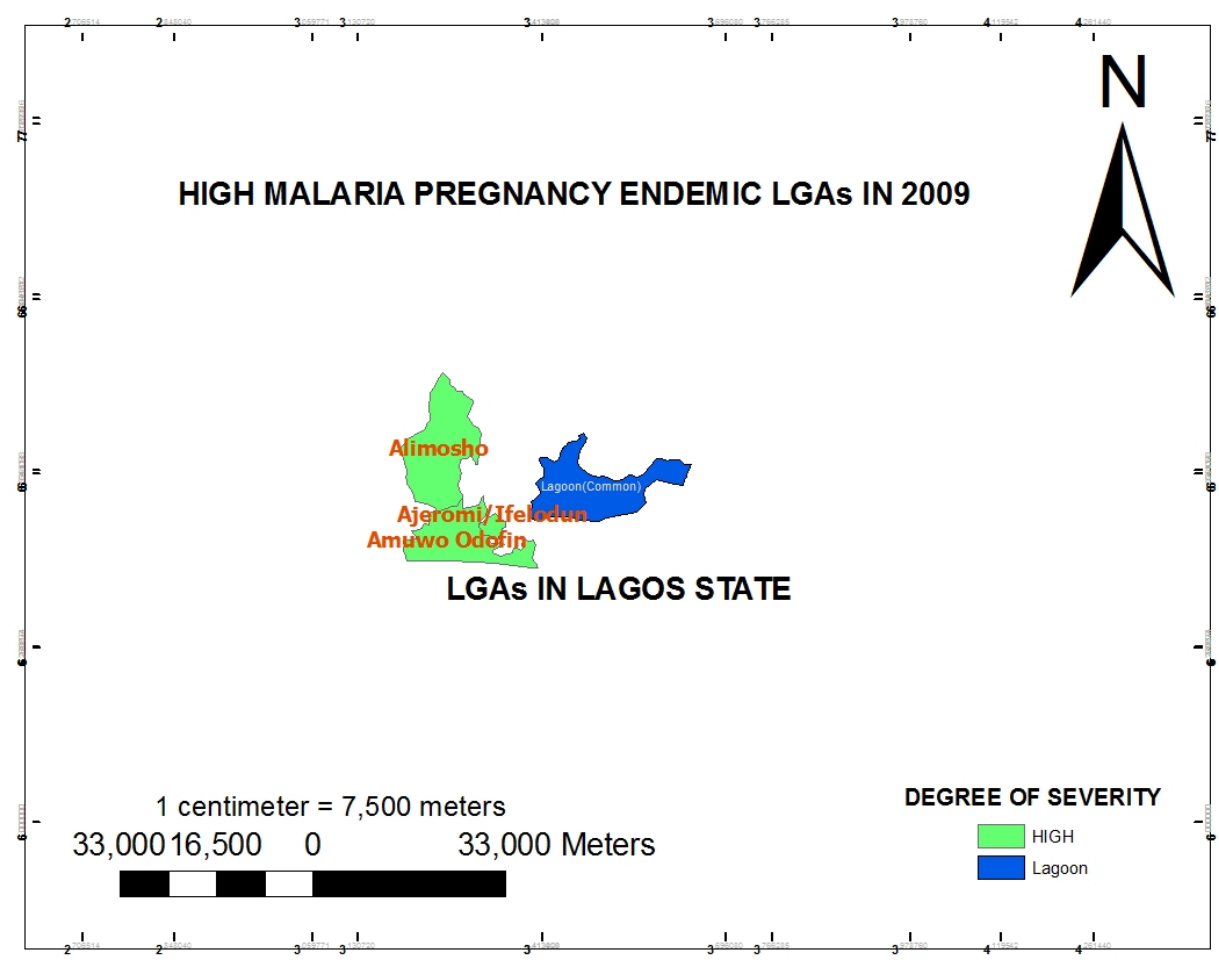

Figure 11: Local Government Areas with high malaria pregnancy endemic in 2009

Table 10: Student's Independent Sample T-test table

\begin{tabular}{|c|c|c|c|c|c|}
\hline & \multicolumn{2}{|c|}{ Mean \pm S.D. } & \multirow{2}{*}{$\begin{array}{c}\text { Mean } \\
\text { difference }\end{array}$} & \multirow{2}{*}{$t$-value } & \multirow{2}{*}{$p$-value } \\
\hline & wet & dry & & & \\
\hline $\begin{array}{c}\text { Malaria Prevalence } \\
\text { Equal Variance assumed }\end{array}$ & $\begin{array}{r}465988.40 \\
\pm 65657.48\end{array}$ & $\begin{array}{l}213737.40 \\
\pm 23514.76\end{array}$ & 252251 & 8.088 & 0.004 \\
\hline
\end{tabular}

Seasonal variations (wet and dry seasons): $t(8)=8.088, p=0.004$

\subsection{Mapping of Malaria Cases in Local Government Areas of Lagos}

The geographical mappings of malaria prevalence cases for Lagos State based on the State 20 Local Government Areas are shown in Figures $(6,7,8,9,10,11,12,13$ \& 14). Two main malaria cases where used for this section and that is the records coming from those with severe malaria cases and the malaria cases among pregnant when. Furthermore, only two years that is 2009 and 2013 were considered under this section. The mappings seek to show local government areas with high malaria endemic prevalence and local government with low malaria endemic prevalence within 2009 and 2013.

Local government areas having an annual record of 5000 severe cases and below were considered to be malaria endemic areas. On the other hand, local government areas that recorded above 5000 severe malaria cases in a year are ranked considered to be high malaria endemic areas. In the same vein, Local government areas that had recorded malaria among pregnant women of 3000 malaria cases and below falls under the low endemic areas of the State, while annual record with more than 3000 cases among pregnant women are rank as high endemic 
malaria local government area.

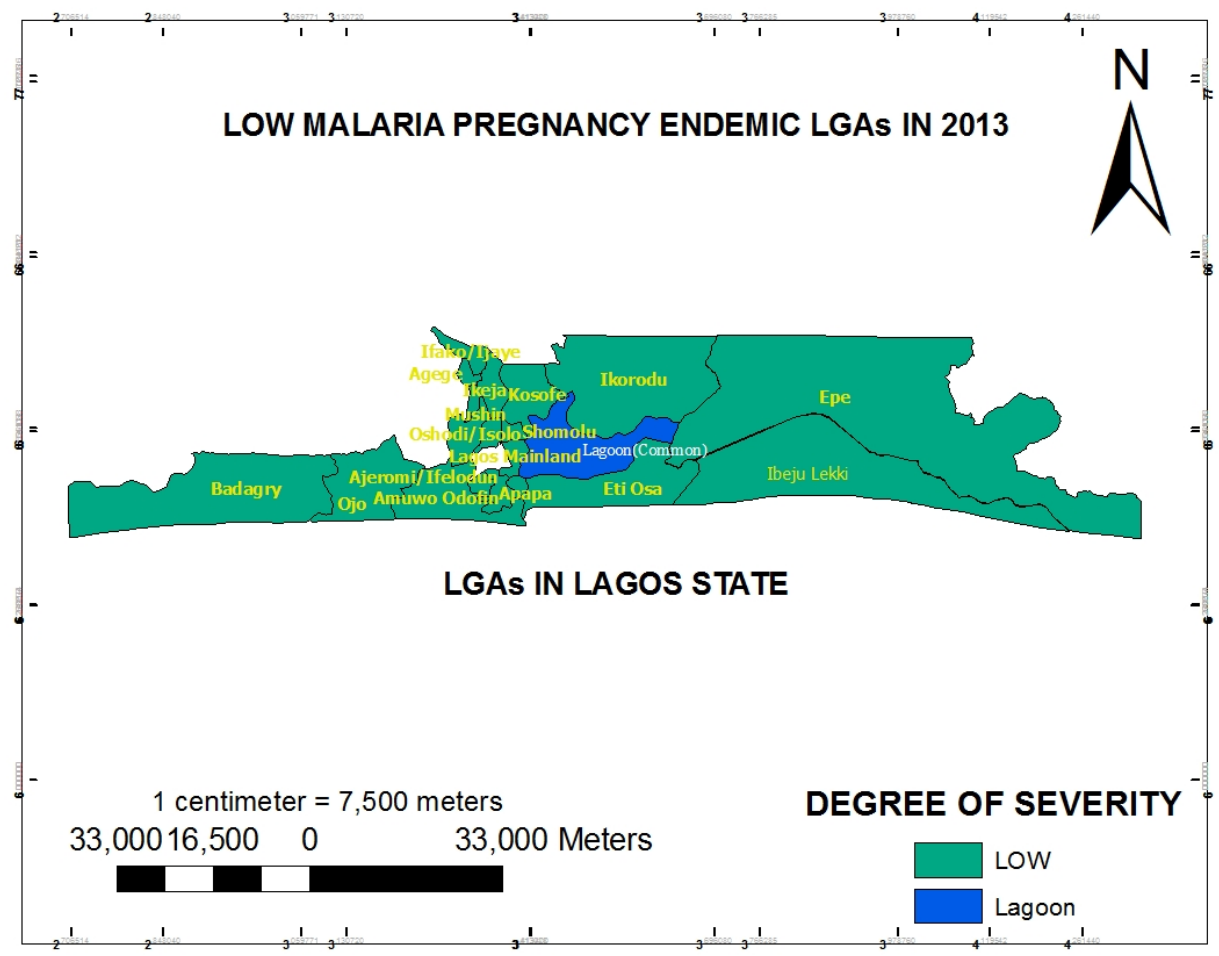

Figure 12: Map representation of Local Government Areas having Low malaria pregnancy endemic in 2013

\subsection{Summary of Findings of the Result}

1. Recent studies show a decline in prevalence of malaria in various Local Government Areas from 2010 to 2012, but however, 2013 witness an increase of this prevalence figure in Lagos.

2. Alimosho Local Government Area has consistently been on the rise of malaria severe and malaria among pregnant women cases for the past consecutive years (2011-2013).

3. From this study, it is observed that with a coefficient of determination (R2) of $13.3 \%$, the environmental factors are responsible for only $13.3 \%$ of the malaria prevalence rate. The (R2) might not have adequately accounted for these environmental factors.

4. Environmental variables of relative humidity and temperature have an inverse relationship with the prevalence rate which is very much in line with previous studies done in this area. However, there is a direct relationship with rainfall and malaria prevalence.

5. A regression model was developed which can act as a predictive factors with other things being equal.

6. Independence sample t-test shows that there is a significant relationship between seasonal variation of Wet and Dry season with the malaria prevalence rate. Furthermore, 
the mean of malaria prevalence during the Wet season is higher than the malaria prevalence during the dry season.

7. Correlating the population density with the various malaria cases often shows a positive weak linear correlation between these various cases and the population density. Occasions also present itself were the correlation is negatively correlated to the population density.

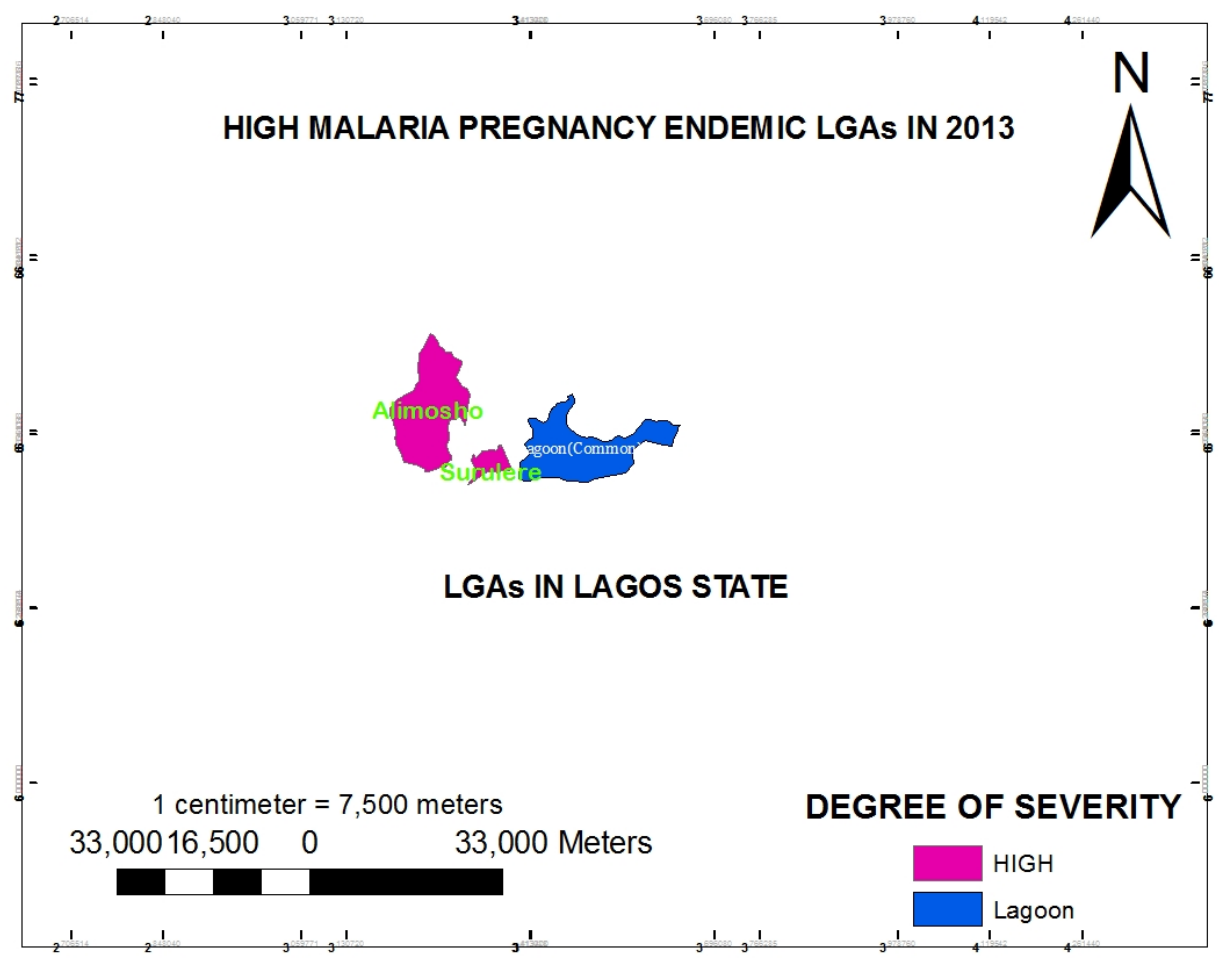

Figure 13: Local Government Areas with high malaria pregnancy endemic in 2013

\subsection{Conclusion}

The purpose of this study was to see the effects of environmental factors on malaria prevalence and the epidemiological framework to quantify State wide prevalence of malaria transmission to human populations. The findings from this research show that environmental variables only are not strong enough to determine the significant level of the prevalence of malaria within the State. Environmental factors of rainfall, temperature and humidity tends to greatly influence the breeding of vector carrying parasite, but these factors can however aid vector mosquitoes carriers in transmitting malaria parasite to human population. Furthermore, with the combination of other non-climatic factors like demographics, socio-economic activities of the populace, biological factors, National Health Care Status and ecological zonation, etc., and climatic factors, these have great influence on the prevalence rate of malaria in Lagos State.

The following are the summary of findings observed:

A number of researchers have found a strong correlation between the malaria prevalence rate 


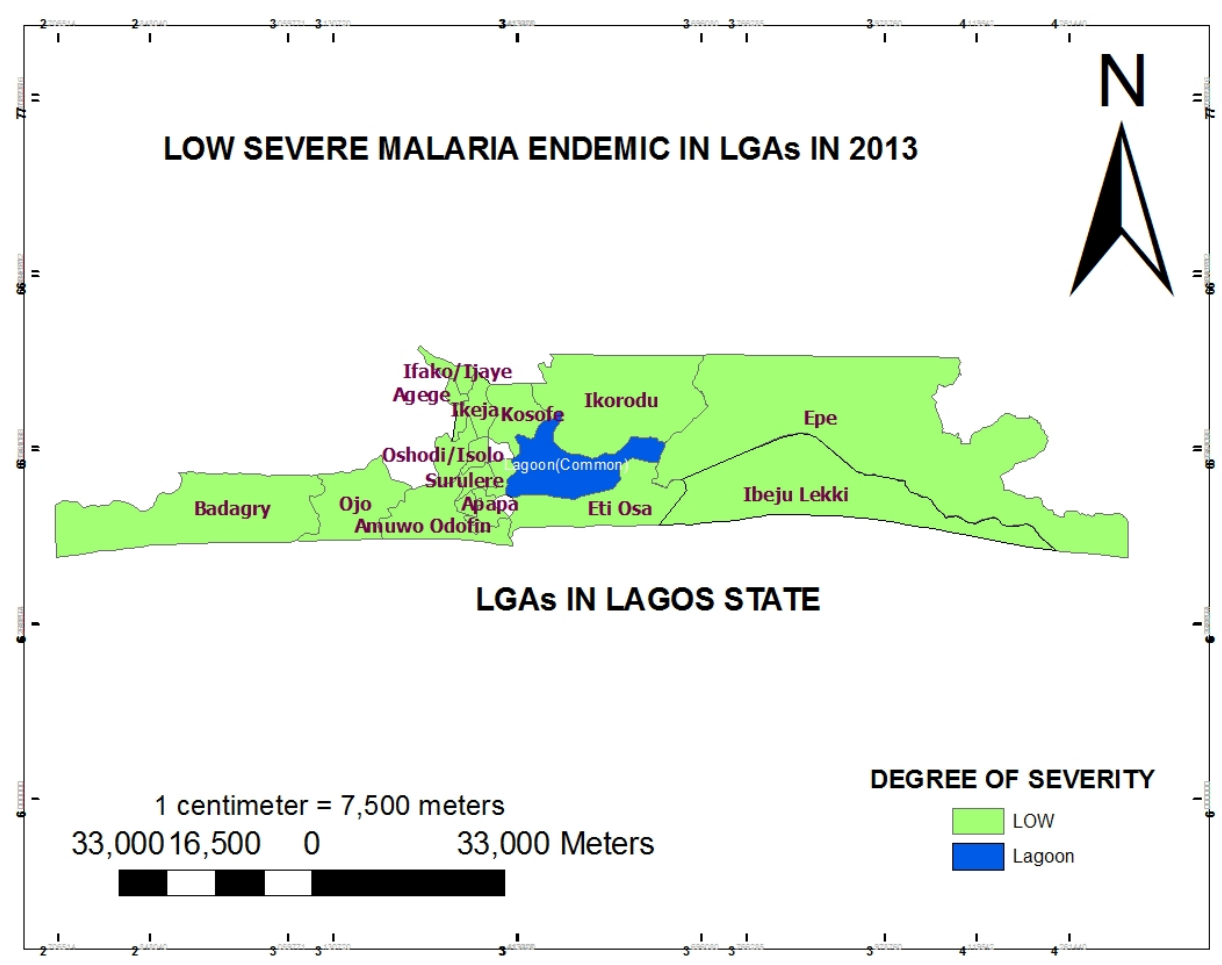

Figure 14: Endemic Local Government Areas in 2013 with low severe malaria cases

and variations in the environmental variable during several preceding months, or with inter annual variation in these variables. In many studies, humidity, temperature and rainfall are considered major risk factors that affect the life cycle and breeding of mosquitoes, and this study confirmed that. More so, the correlation model shows a weak correction between malaria prevalence and rainfall, this confirmed that only reasonable amount of rainfall can create additional breeding sites for mosquitoes, thereby, increasing its population, excess of rainfall wash off the eggs and larvae of mosquito due to erosion, however, stagnated water increases the breeding ground for mosquitos. Considering only environmental factors in statistical models to predict malaria incidence or prevalence rate is complex, and not yet well understood. This has made some researchers to develop models, in which incidence and prevalence rates are standardized with respect to non-climatic variable, so that the influence of climate on fluctuations in the malaria rate can be seen more clearly.

A close observations to this studies shows Local Government Areas where malaria cases recorded high cases are, most often-than-not Local Government Areas having serious sanitation problems such as blocked or very poor drainage system, poor waste disposal system and dirty neighborhood generally. This creates lots of habitat for mosquitoes to breed. Activities like this could greatly increase the malaria risk on the human population which may lead to higher prevalence and incidence of malaria in the society without the influence of climatic factors causing this increase. Other non-climatic factors such as socio-economic and health care status of the communities within the Local Government Areas can greatly influence either positively or negatively the malaria risk on the population. The combination of both the climatic and non-climatic factors is a good indictor to determine the prevalence and incidence rate of malaria in Lagos State. 


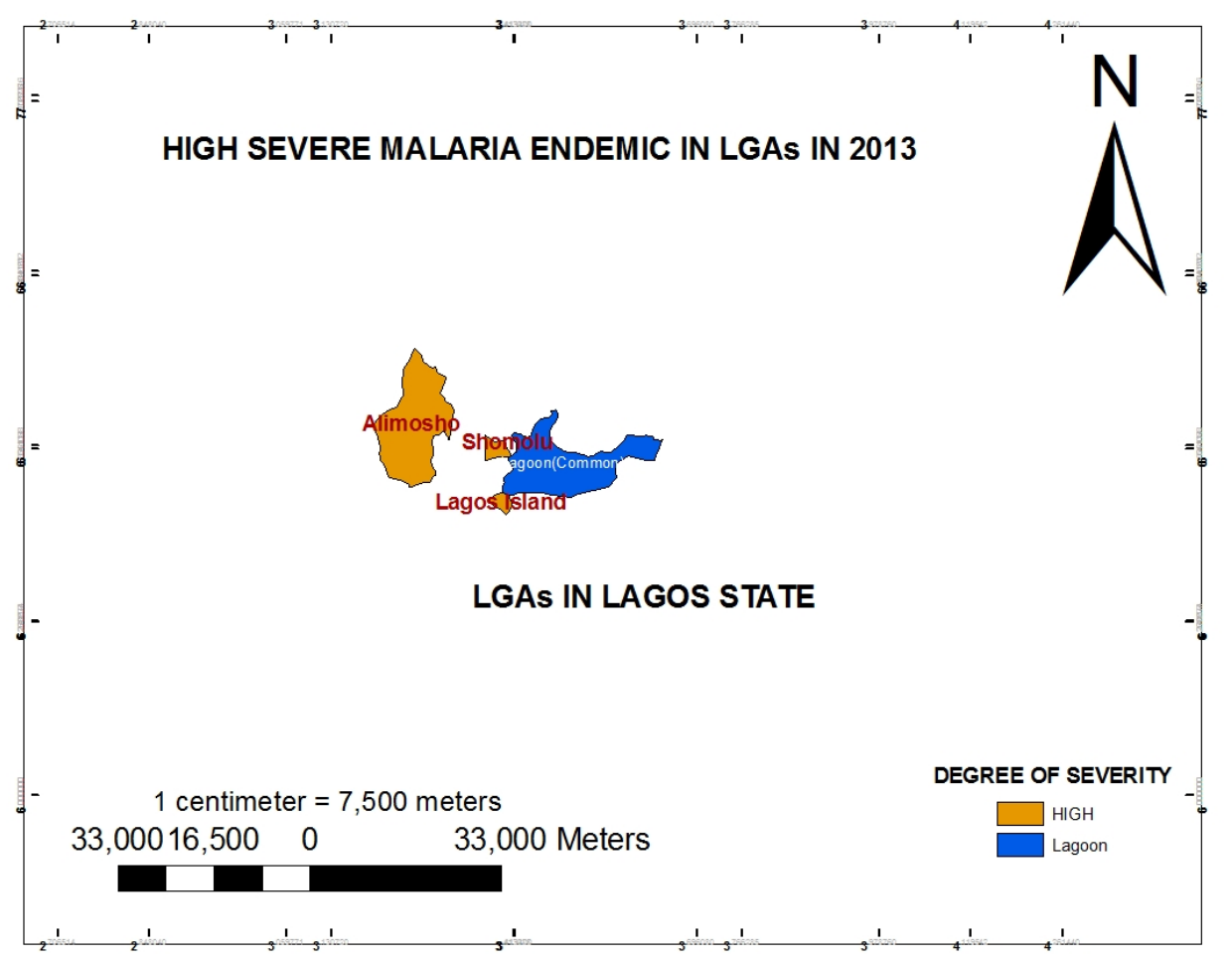

Figure 15: Areas with high severe malaria endemic in 2013

Another finding revealed was the declined of number of malaria cases within the Local Governments Areas most especially from 2010-2012. This decline may not be linked to unfavorable environmental factors of rainfall, temperature and relative humidity that may have occur during this period but rather it can be greatly attributed to the increased of intervention Nigeria received from donor agencies and organizations that help in combating malaria epidemic globally. Nigeria has benefited from increasing support from various partnerships in the fight against malaria. Currently, the largest partners in terms of funding are the Global Fund, including the Affordable Medicines Facility - malaria (AMFm) program, the World Bank, President's Malaria Initiative (PMI) by the US Government, and the United Kingdom Department for International Development (DfID). Other key partners include the Clinton Health Access Initiative, the United Nations Children's Fund (UNICEF), and the World Health Organization (WHO). Nigeria has been a beneficiary country of over $\$ 1$ billions from 2009-2013 (WHO, 2014) from these various donor partners. These interventions is to help the country scale up its malaria prevention and treatment campaign, hence a National Malaria Control Program (NMCP) was developed. The NMCP Strategic Plan 2009-2013 which is based on the National Strategic Health Development Plan 2010-2015 and in line with National Health and Development priorities. The strategy Plan outlines the provision of a comprehensive package of integrated malaria prevention and treatment through the community, primary, secondary, and tertiary levels. The strategy Plan also defines the roles of each health care worker relative to malaria case management and control across all health care services including public, private (including for-profit and not-for-profit), PMVs, and the traditional health providers. Furthermore, the strategy Plan seeks to achieved continuous scale up coverage of the most vulnerable groups - children under five years of age and pregnant women 
- with proven preventive and therapeutic interventions, including artemisinin-based combination therapies (ACTs), insecticide-treated nets (ITNs), intermittent preventive treatment of pregnant women (IPTp), and indoor residual spraying (IRS).

Taking antecedent from the above, it can been seen clearly that decreased experience during these period was largely due to the effort made by the various donor partners in combating malaria ensuring that it actually roll back. This has little or nothing to do with the environmental variations. However 2013, experiences an upraised because some of the intervention funds were either reduce or stopped at that period because of the corrupt activities on the part of the implementation officials.

\section{Recommendation}

The following recommendations are proffer from this research work:

1. Lagos State which is a cosmopolitan state is characterized by urban climate and weather conditions as a result of the cosmopolitan activities that takes place within the state. This can greatly affects the state monthly mean temperature and other climatic variations to such a level that can aid rapid growth and breeding of the vector carrying malaria. Thus it is recommended that eco- friendly activities should be greatly encouraged by all the relevant industrial players in the State. Also, government policy should guide against any form of indiscriminate disposal of industrial and clinical waste that can have an adverse effect on the environment in any form. This is to maintain a clear and healthy environment in the State.

2. Factors related with population vulnerability are also critically important in malaria transmission. The presence of parasite resistance to the usual anti- malaria and to insecticides, population movements and the presence of other underlying infections are responsible for a large part of the variability in the prevalence of malaria. Government should ensure to building of more health facilities and better equip the existing ones in order to effectively serve the exploding population of the State. More so, government should carry out regular indoor residual spraying (IRS) exercise across the Local Government Areas, and continue on the intermittent preventive treatment of pregnant women (IPTp), subsidized the artemisinin-based combine therapies (ACTs) and insecticide-treated nets (ITNs). These consolidated efforts along with other efforts from donor agencies can help roll back malaria and reduces the occurrences to a very significant low level.

3. There should be a better and meaningful understanding of the dynamics of disease transmission, including its associated spatial and temporal patterns, among health workers and those carrying out monitoring and evaluation. This knowledge when shared and apply can better help towards preempting disease outbreaks. Monitoring and Evaluation (M\&E) strategy should be establish to harmonized M\&E system this can be used by all partners to monitor progress towards agreed-on targets and is used to manage and adjust interventions based on evidence.

4. The need to develop accurate maps of malaria transmission cannot be over emphasized. This can greatly guide interventions strategies, and thus optimize the use of limited and financial resources to areas of utmost need. In addition, early warning systems can be 
developed to predict epidemics of malaria from environmental changes.

5. Geographic modeling and analysis add an important technical element to epidemiology that has only recently been subjected to scientific exploration. Opportunities to utilize spatial technologies to provide real-time assessments of disease risk are now available to the public health community. As remote sensing technology and GIS improves and epidemiological methods are refined, disease predictions could soon be as common as those of the weather. Yet, it is important to continue studying diseases we know most about; as the environmental conditions of the world change, so do patterns of disease transmission. For those reasons, further research into the application of remote sensing and GIS technologies with the aim of creating preemptive disease intelligence is not only scientifically beneficial, but a human necessity and moral obligation.

6. The GIS spatial model developed for this study could be improved upon by a more stringent decision rule and inclusion of more variables. A thorough assessment of the input's classification schema and individual analysis of their predictive strength would vastly improve reliability of model outcomes. Furthermore, higher spatial resolution imagery and observed incidence rates recorded at the community level would allow prediction of malaria risk on a local scale to the entire regional or even nationwide scale.

\section{References}

[1] Assaf Anyamba, Kenneth J Linthicum, and Compton J Tucker. "Climate-disease connections: Rift Valley fever in Kenya". In: Cadernos de saude publica 17 (2001). President's Malaria Initiative: Nigeria Malaria Operational Plan FY 2013, U.S. Global Malaria Coordination pp. 9-15., S133-S140.

[2] Mark E Beatty et al. "Mosquitoborne infections after Hurricane Jeanne, Haiti, 2004". In: Emerging infectious diseases 13.2 (2007), p. 308.

[3] Louisa R Beck, Bradley M Lobitz, and Byron L Wood. "Remote sensing and human health: new sensors and new opportunities." In: Emerging infectious diseases 6.3 (2000), p. 217.

[4] John C Beier, Gerry F Killeen, and John I Githure. "Entomologic inoculation rates and Plasmodium falciparum malaria prevalence in Africa." In: The American journal of tropical medicine and hygiene 61.1 (1999), pp. 109-113.

[5] Peng Bi et al. "Climatic variables and transmission of malaria: a 12-year data analysis in Shuchen County, China." In: Public health reports 118.1 (2003), p. 65.

[6] Simon Brooker, Simon I Hay, and Don AP Bundy. "Tools from ecology: useful for evaluating infection risk models?" In: Trends in parasitology 18.2 (2002), pp. 70-74.

[7] Simon Brooker et al. "Spatial clustering of malaria and associated risk factors during an epidemic in a highland area of western Kenya". In: Tropical medicine $\mathscr{E}$ international health 9.7 (2004), pp. 757-766.

[8] Leonard Jan Bruce-Chwatt, Julian De Zulueta, et al. The rise and fall of malaria in Europe: a historico-epidemiological study. Published for the Regional Office for Europe of the World Health Organization by Oxford University Press, Walton Street, Oxford OX2 6DP, 1980. 
[9] B Carme et al. "Plasmodium prevalence and parasitic burden in blood donors of Brazzaville, Congo". In: Annales de la Societe belge de medecine tropicale. Vol. 73. 3. 1993, pp. $179-187$.

[10] Fabrice Carrat and Alain-Jacques Valleron. "Epidemiologic mapping using the "kriging" method: application to an influenza-like epidemic in France". In: American journal of epidemiology 135.11 (1992), pp. 1293-1300.

[11] CDCP. 2007, 2009. Centers for Disease Control and Prevention. URL: http: //www . cdc.gov.

[12] Monica Cheesbrough. District laboratory practice in tropical countries. Cambridge university press, 2006.

[13] Keith C Clarke, Sara L McLafferty, and Barbara J Tempalski. "On epidemiology and geographic information systems: a review and discussion of future directions." In: Emerging infectious diseases 2.2 (1996), pp. 85-92.

[14] Marlies H Craig, RW Snow, and David le Sueur. "A climate-based distribution model of malaria transmission in sub-Saharan Africa". In: Parasitology today 15.3 (1999), pp. 105-111.

[15] Ellen K Cromley. "GIS and disease". In: Annual review of public health 24.1 (2003), pp. $7-24$.

[16] Randall Culpepper and Patrick Kelley. "DOD-global emerging infections surveillance and response system". In: Navy Medicine 93.5 (2002), pp. 10-14.

[17] U Deichmann. "African population database. Digital database and documentation". In: National Center for Geographical Information and Analysis, Santa Barbara (1996).

[18] RC Dhiman. "Remote sensing: a visionary tool in malaria epidemiology". In: ICMR Bull 30.11 (2000), pp. 1-2.

[19] Maria A Diuk-Wasser et al. "Mapping rice field anopheline breeding habitats in Mali, West Africa, using Landsat ETM+ sensor data". In: International Journal of Remote Sensing 25.2 (2004), pp. 359-376.

[20] J Dossou-Yovo et al. "The impact of rice fields on malaria transmission in the city of Bouaké, Côte d'Ivoire". In: Bulletin de la Societe de pathologie exotique (1990) 91.4 (1998), pp. 327-333.

[21] TT Epidi, CD Nwani, and NP Ugorji. "Prevalence of malaria in blood donors in Abakaliki Metropolis, Nigeria". In: Scientific Research and Essays 3.4 (2008), pp. 162-164.

[22] FAO. "Report on the agro-ecological wnes project. Vol. I. Methodology and results for Africa". In: World Soil Resources Report 48/1 (1978).

[23] M. Ghulam et al. "Malaria prevalence in Sindh". In: Med . Channel 10.2 (2004), pp. 4142.

[24] Gregory E Glass. "Update: spatial aspects of epidemiology: the interface with medical geography". In: Epidemiologic reviews 22.1 (2000), pp. 136-139.

[25] C Guinovart et al. "Malaria: burden of disease". In: Current molecular medicine 6.2 (2006), pp. 137-140. 
[26] Federal Ministry of Health. National Malaria Control Programme : A Road Map for Impact on Malaria in Nigeria - A 5year Strategic Plan 2006-2010. URL: http://www . health.gov.ng/.

[27] World Health Organization. 2003, WHO Country Cooperation Strategy 2004-2008, Democratic People's Republic of Korea; Democratic People's Republic of Korea; 2005, Republic of Korea: Country Profile. World Health Organization: Roll Back Malaria Monitoring and Evaluation. URL: http://www.who.int/.

[28] Masoud Salehi et al. "Spatial modeling of malaria incidence rates in Sistan and Baluchistan province, Islamic Republic of Iran." In: Saudi medical journal 29.12 (2008), pp. 17911796.

[29] Robert K Washino and Byron L Wood. "Application of remote sensing to arthropod vector surveillance and control". In: The American journal of tropical medicine and hygiene 50.6 Suppl (1994), pp. 134-144.

[30] Jason Wilder. "Modeling Malaria Transmission Risk Using Satellite-based Remote Sensing Imagery: A Five-year Data Analysis in Democratic People's Republic of Korea: a Thesis Presented to the Department of Geology and Geography in Candidacy for the Degree of Master of Science". PhD thesis. Northwest Missouri State University, 2007. 